*Professora Adjunta na Universidade de Rio Verde UNIRV/GO. Doutoranda em Direito na Universidade do Vale do Rio dos Sinos - S.L./ RS. Mestre em Direito pela Universidade de Ribeirão Preto - UNAERP/SP. Especialista em Direito Tributário pela UCG Goiânia/GO.

**Advogado. Professor adjunto da Universidade Rio Verde (UNIRV) - GO. Doutorando em Direito pela UNICEUB. Bolsista CAPES/CNPq. Mestre em Direito, Relações Internacionais e Desenvolvimento pela PUC-GO. E-mail: coutolacerda@hotmail. com

***Advogada. Professora adjunta da Universidade Rio Verde (UNIRV) - GO. Doutora em Direito pela PUC-SP. Mestre em Direito pela Unitoledo. E-mail: estefanialino@msn.com

\section{Análise das Mutações Constitucionais à Luz da Crítica Hermenêutica do Direito}

\author{
Analysis of Constitutional Changes from the \\ Perspective of Hermenutical Criticism of the LaW
}

\section{Patrícia Spagnolo Parise Costa* Murilo Couto Lacerda** Estefânia Naiara da Silva Lino***}

Como citar: COSTA, Patrícia Spagnolo Parise; LACERDA, Murilo Couto; LINO, Estefânia Naiara da Silva. Análise das mutações constitucionais à luz da crítica hermenêutica do Direito. Revista do Direito Público, Londrina, v. 15, n. 1, p. 61-84, abr. 2020. DOI: 10.5433/24157-108104-1.2020v15n1p. 61. ISSN: $1980-511 \mathrm{X}$

Resumo: Sob o argumento da busca pela efetividade das normas constitucionais, em especial, daquelas definidoras de direitos fundamentais, a prática interpretativa do Supremo Tribunal Federal tem produzido as chamadas mutações constitucionais, cujas raízes se encontram no direito alemão. No Brasil, contudo, em que, aparentemente, há carência de uma identidade própria em termos de teoria jurídica, mormente, da decisão, questionouse se tal atuação tem caráter ativista, especialmente sob o prisma da Crítica Hermenêutica do Direito. Objetivou-se, com o estudo, analisar o instituto da mutação constitucional a partir de seus elementos históricos, de forma a pontuar sua legitimidade e adequação à prática jurídica brasileira, a partir dos fundamentos filosóficos que orientam a teoria Crítica Hermenêutica do Direito, em contraposição aos parâmetros interpretativos do Supremo Tribunal Federal. Para tanto, valeu-se pesquisa exploratória, envolvendo levantamento bibliográfico e do método histórico. Concluiu-se que a produção de mutações constitucionais decorre de uma postura decisionista/discricionária do Supremo Tribunal Federal, configurando ativismo e ferindo os preceitos do Estado Democrático de Direito. Sob o prisma da Crítica Hermenêutica do Direito não é um instituto legítimo.

Palavras-chave: Direitos. Supremo Tribunal Federal. Ativismo. Mutações constitucionais. Teoria Crítica do Direito.

Abstract: Under the argument of the search for the effectiveness of constitutional norms, especially those that define fundamental rights, the interpretative practice of the Federal Supreme 
Court has produced many constitutional mutations, which can be traced back to German law. In Brazil, however, there is an apparent lack of identity in its own legal theory, especially in regards to judicial decisions. Many have questioned whether these decisions have an activist tendency, especially from the point of view of Hermeneutic Criticism of Law. Moreover, the purpose of this paper is to analyze the institute of constitutional mutation from its historical elements, in order to understand its legitimacy and adequacy in the Brazilian legal system from the philosophical foundations that guide the theory of Hermeneutic Criticism of Law, in opposition to the interpretative parameters of the Federal Supreme Court. Likewise, exploratory research and literature review was used for the same reason. This paper concludes that the production of constitutional mutations derives from a decisionist/discretionary posture of the Supreme Court, configuring activism and hurting the precepts of the Democratic State of Law. Moreover, from the point of view of Hermeneutic Criticism of Law, it is not a legitimate institute.

Keywords: Rights. Federal Court of Justice. Activism. Constitutional mutations. Critical Theory of Law. 


\section{INTRODUÇÃO}

A mutação constitucional tem sua origem no direito alemão e está inserida em diversas doutrinas de Direito Constitucional no País. Entendida como expressão do poder constituinte difuso, tem, em tese, o objetivo de compatibilizar a Constituição com o dinamismo dos fatos sociais, ou seja, trazer efetividade à Constituição a partir da alteração pela atividade jurisdicional do conteúdo da norma, sua significação e alcance, sem qualquer modificação no texto constitucional.

É algo que tem se tornado bastante comum na prática interpretativa dos ministros do Supremo Tribunal Federal brasileiro, a partir do argumento de que uma Constituição não pode ficar engessada diante da dinâmica social e mais, que não se pode ficar aquém dos fatores reais de poder que norteiam a sociedade (LASSALLE, 2013). Devem-se, então, buscar maneiras de manter o corpo constitucional atualizado, em uma realidade legislativa que nem sempre traz essa possibilidade. Tanto mais porque o modelo adotado pela Constituição brasileira se caracteriza pela presença de normas programáticas, o que relativiza a efetividade jurídica e social das normas constitucionais.

Entretanto, tais argumentos mostram que a atuação interpretativa do Supremo Tribunal Federal tem convergido para a visão positivista a qual tanto rebate. Aparentemente, a teoria jurídica brasileira, em especial, no que tange à decisão judicial se mostrado sem identidade própria, unindo aspectos do positivismo kelsiano e hartiano, e da teoria argumentativa alexyana, pautando-se pela discricionariedade e pela ponderação de valores, esta norteada pelo princípio da proporcionalidade, o que acaba levando a decisões que promovem insegurança jurídica e denotam uma atitude proativa da jurisdição.

Desta forma, tem emergido acirradas discussões no âmbito da ciência jurídica, já que não há um consenso sobre a legitimidade da corte constitucional brasileira em termos de interpretação de diversos casos que envolvam direitos fundamentais. Em especial, sob o prisma da teoria Crítica Hermenêutica do Direito, que pontua sérios problemas ao modelo de decisão judicial no Brasil, inclusive, no que diz respeito às mutações constitucionais decorrentes dessa prática.

Neste cenário, emergiram os seguintes questionamentos: sob o prisma da teoria Crítica Hermenêutica do Direito, a mutação constitucional seria um instrumento legítimo de modificação constitucional e apropriado para reafirmar a força normativa da Constituição brasileira, na busca de concretização de suas normas, em especial, daquelas definidoras de direitos fundamentais? Este tipo de reforma, decorrente do chamado Poder Constituinte Difuso, configuraria prática ativista?

A importância deste estudo repousa, como se observa, na atualidade do tema e na polêmica que o envolve. Não é assunto novo, contudo, ainda hoje sucinta discussão em nome de uma atuação legítima do Poder Judiciário, mormente do Supremo Tribunal Federal, de forma a preservar os preceitos do Estado Democrático de Direito. Ademais, há de se lembrar de que as decisões em âmbito de jurisdição constitucional têm um impacto em toda a sociedade e no próprio direito 
brasileiro.

Objetiva-se, portanto, analisar criticamente o fenômeno da mutação constitucional, sua legitimidade no âmbito da interpretação feita em sede de jurisdição constitucional e se sua prática seria legítima ou denotaria ativismo judicial, de acordo com os fundamentos da Crítica Hermenêutica do Direito, em contraposição aos parâmetros adotados pelo Supremo Tribunal Federal para fins de interpretação constitucional e consequente produção de mutações. Para tanto, pretende-se verificar, brevemente, o contexto de nascimento da mutação constitucional, o percurso histórico da teoria da decisão desde o positivismo até o pós-positivismo, para que se possa tecer as devidas críticas ao instituto, na perspectiva da Crítica Hermenêutica do Direito.

Para a realização da pesquisa, o método de abordagem será o dedutivo. Em relação ao procedimento, será utilizado o método histórico. A técnica de pesquisa escolhida é a de documentação indireta, mais especificamente, a bibliográfica, abrangendo as fontes sobre a temática estudada (revistas científicas especializadas, livros, exemplos de casos julgados pelo Supremo Tribunal Federal, entrevistas, teses etc.).

\section{DAS MUTAÇÕES CONSTITUCIONAIS}

Inicialmente, importa tratar sobre o conceito de mutação constitucional, bem como do contexto histórico em que emergiu tal instituto, além de alguns casos exemplificativos já julgados pelo Supremo Tribunal Federal para que se possam situar as críticas que envolvem a questão de sua legitimidade e adequação à teoria da decisão no Brasil, em especial, no âmbito da teoria Crítica Hermenêutica do Direito, delineada por Lenio Luiz Streck, a partir da análise da visão que predomina na corte constitucional brasileira, especialmente, a do ministro Luís Roberto Barroso.

\subsection{Conceito, Noções Históricas e Características do Fenômeno}

Na doutrina pátria, Bulos (2015) ensina que mutação constitucional é o fenômeno por intermédio do qual o poder constituinte difuso se manifesta, ocorre na situação em que os textos constitucionais são alterados, sem revisões ou emendas constitucionais.

As constituições, como organismos vivos que são, acompanham o evoluir das circunstâncias sociais, políticas, econômicas, que, se não alteram o texto na letra e na forma, modificam-no na substância, no significado, no alcance e no sentido de seus dispositivos (BULOS, 2015, p. 120).

Não é fenômeno recente, tendo sido identificado já no final do século XIX pelos autores tedescos, passando a ser estudado na Espanha, na Itália, em Portugal e, também, na América Latina, pelo México, Venezuela e Brasil. A primeira vez que o termo foi utilizado na literatura jurídica foi na obra Wandlungen der deutschen Reichsverfassunganderung, de Paul Laband, escrita em 1895. Nesse livro foi introduzida a diferenciação entre reforma constitucional - Verfassungänderung - e 
mutação constitucional - Verfassungswandlung (KUBLISCKAS, 2009).

Neste contexto, Sánchez Urrutia (2000, p. 105) explica que:

El problema de los cambios informales de la Constitución es destacado por la doctrina publicista alemana de finales del siglo XIX y principios del XX. En este contexto, se formula el término de «mutaciones constitucionales» (verfassungswandlung) para describir el cambio de significado o sentido de la Constitución sin que vea alterada su expresión escrita. Son autores de la Escuela Alemana de Derecho Público los primeros en tratar de forma directa este fenómeno. Los postulados de esta escuela, en cuanto propugna el estudio dogmático del derecho público, constituyen el punto de partida necesario para plantearse el problema de la mutación constitucional en cuanto cambio de la realidad constitucional al margen de los procedimientos formales de reforma.

A questão da mutação constitucional surgiu sob um prisma formalista, o que pode ser observado nas obras de Laband e também de Georg Jellinek, que a refutavam no contexto de um positivismo ainda legalista. Contudo, parte da doutrina alemã, de visão antiformalista, representada, entre outros, por Rudolf Smend, buscou integrar a mudança informal a um conceito mais complexo de Constituição, que passa a ser descrita como um corpo dinâmico que interage de maneira contínua com a realidade política (SÁNCHEZ URRUTIA, 2000).

Segundo Bonavides (2006, p. 180) "foi Smend dos mais agudos em assinalar a importância da mudança constitucional, ultimada fora dos processos formais explícitos e técnicos de reforma da Constituição.”

Vale abrir um parêntese para ressaltar que tal pensamento de Smend alinhava-se com a corrente chamada Jurisprudência dos Valores ${ }^{1}$, que tomou corpo na Alemanha após a Segunda Guerra. Neste mesmo cenário, Streck (2017a, p. 117) explica que: "na Alemanha a existência da jurisprudência dos valores encontra-se explicada na busca de uma fuga da legalidade estrita imposta por países vencedores da guerra".

Veja-se que a mutação constitucional nasceu, portanto, em um contexto histórico específico, em consonância com a realidade alemã, que é bastante diferente da brasileira. Nas palavras de Streck (2017a, p. 117): "No Brasil, a Jurisprudência dos Valores, como tantas outras correntes, foi importada e recepcionada de forma equivocada, sem consideração de nosso contexto histórico."

E a propósito da atuação da corte constitucional brasileira, no que tange à produção de mutações constitucionais, parte da doutrina pátria trata do instituto como um instrumento propiciador da efetividade das normas constitucionais, desde que respeitados certos limites, a exemplo de Kublisckas (2009), que em obra específica sobre o assunto, trata de seu conceito, características e balizes: a) informalidade: as modificações decorrem da interpretação das normas constitucionais, das práticas e costumes constitucionais; b) pluralidade de agentes: as mutações

1 Com a jurisprudência dos valores, sustentava-se um ius distinto da lex através da invocação de argumentos que permitissem ao tribunal recorrer a critérios decisórios que se encontravam fora da estrutura rígida da legalidade (STRECK, 2017a, p. 115). 
podem ser realizadas pela atuação dos agentes estatais autorizados, bem como da sociedade civil, por meio da opinião pública, grupos de pressão, construções de juristas; c) distanciamento no tempo: a mutação pode acontecer por meio de lenta consolidação de um novo entendimento sobre um dispositivo constitucional, mediante a comparação entre a compreensão presente e a pretérita de determinado dispositivo, ou, ainda, de forma mais radical, como naquelas ocasiões em que um tribunal fixa novo entendimento sobre matéria já pacificada; d) manutenção do texto/modificação da norma: as mutações mudam a norma constitucional sem mudar o texto da Constituição; e) sujeição a limites: as mutações somente serão legítimas quando introduzidas com o objetivo de desenvolver, atualizar ou complementar as normas constitucionais escritas, não podendo contrariálas.

Há de se analisar, ainda na perspectiva do autor, que o caráter de abertura e elasticidade de uma Constituição pode influenciar em uma maior ou menor prática mutacional. Ou seja, quanto maior for a natureza principiológica da Constituição, maior o número de situações em que ocorrerão as mutações constitucionais. Isso porque as normas que representam princípios podem oferecer várias opções de concretização, todas válidas. Além disso, os interesses constitucionalmente tutelados, estando em uma posição contraditória, levarão o intérprete a buscar a harmonização dos preceitos no caso concreto. E a existência de normas que admitem ou carecem de regulamentação é mais um fator que favorece a proliferação das mutações constitucionais (KUBLISCKAS, 2009).

Ainda justificando a produção de mutações constitucionais, Bulos (2015) pontua que outro fator que leva à produção das mutações constitucionais é a inércia legislativa. Este autor entende que, de acordo com jurisprudência do STF, esse é um perigoso fator de peso para o surgimento da reforma informal, porque se o legislador é incumbido pela Constituição de regulamentar determinada norma constitucional e não o faz, acaba transgredindo a própria manifestação do poder constituinte originário.

\subsection{Situando o Problema das Mutações Constitucionais a partir de Casos Julgados pelo STF}

É claro que a inércia dos poderes políticos leva, fatalmente, à judicialização da política. Mas, será que, sob o manto da judicialização, pode o Judiciário proceder à interpretação como ato de vontade, impulsionado por fatores políticos e morais? Eis o grande problema que se coloca em termos de mutação constitucional no Brasil, em que se reforma a norma, muitas vezes, em sentido oposto ao próprio Texto Maior, contrariando os limites referidos por Kublisckas no tópico anterior, o que leva ao questionamento se, de fato, o positivismo ficou para trás.

Ora, para Kelsen, que distinguia direito de ciência do direito, a interpretação nada mais era do que o fruto de uma cisão: a) interpretação como ato de vontade, que levava à produção de normas no momento de sua aplicação e b) interpretação como ato de conhecimento, ou seja, a descrição das normas jurídicas de forma objetiva (STRECK, 2017a).

Apesar de o jusfilósofo austríaco não ter se dedicado propriamente à teoria da decisão 
judicial em sua obra, o fato é que a interpretação como ato de vontade tem sido uma constante na prática judiciária brasileira, dita pós-positivista, conforme será visto no decorrer deste estudo.

Diversos são os exemplos ilustrativos do fenômeno no Brasil. Um deles foi o da Reclamação n. 4.335/AC, que acabou perdendo seu objeto com a criação da Lei n. 11.464/2007. Contudo, interessa pontuar os aspectos que fatalmente, caso a referida lei não tivesse sido editada, levaria à mutação constitucional, expressando prática claramente ativista. Streck (2014, p. 61-62) explica as particularidades do caso:

Com efeito, essa medida foi interposta pela Defensoria Pública do Estado do Acre no intuito de fazer valer entendimento do STF exarado em controle difuso de constitucionalidade (no caso, o problema da progressão de regime nos crimes hediondos). Como se sabe, a medida da reclamação é restrita para fazer cumprir decisões da corte que estejam revestidas de eficácia erga omnes e efeitos vinculantes, como ocorre no âmbito do controle concentrado. Nos casos de pronunciamento da corte em controle difuso, a Constituição, por força do art. $52, \mathrm{X}$, condiciona a suspensão da execução da lei declarada inconstitucional pelo STF à intervenção do Senado. Ocorre que parte dos Ministros entendeu que - em virtude de uma tendência à "concentração" do controle de constitucionalidade, visualizada nas mudanças operadas no texto da Constituição e nas várias leis infraconstitucionais - estaria ocorrendo uma mutação constitucional e que, por isso, no lugar em que a Constituição fala que ao Senado cabe suspender a execução da lei, deveria ser lido dar publicidade à lei declarada, no todo ou em parte, inconstitucional pelo STF.

Observe-se que neste caso, mais do que a mudança no sentido da interpretação do texto, pretendeu-se mudar a própria dicção do art. 52, X da Constituição brasileira.

Outra mutação constitucional se deu em 03/12/2008, quando o STF, no julgamento do RE 466.343, decidiu que não mais caberia prisão civil ao depositário infiel. Com o advento da referida decisão, foi editada a Súmula Vinculante n. 25/2009 com intuito de lhe atribuir o efeito erga omnes.

Mais um exemplo foi o julgamento da ADI 4.277 e da ADPF 132, em 05/05/2011. Na sede destas ações, o Supremo Tribunal Federal reconheceu a união estável entre pessoas do mesmo sexo, inclusive como entidade familiar (LENZA, 2016). Muito se discutiu, no âmbito das duas decisões, sobre a existência de legitimidade para tal atuação e, também, acerca de possível lesão ao princípio democrático e ao da separação dos poderes. E importa ressaltar, inclusive, que ambos os casos houve mutação constitucional sob a justificativa da inércia do Poder Legislativo.

Ademais, tem sido verificada a influência da opinião pública e dos grupos de pressão na produção das mutações constitucionais. Neste âmbito, vale trazer a lúmen um caso particular e bastante recente de mutação constitucional: a decisão polêmica proferida em 17 de fevereiro de 2016 e confirmada no dia 2 de setembro de 2016, no Habeas Corpus n. 126292, quando o Plenário, mudando sua jurisprudência anterior, admitiu a execução provisória da pena de prisão antes do trânsito em julgado, quando decisões de segundo grau confirmam condenações criminais (BRASIL, 
2015b). A referida decisão contrariou, na literalidade, o preceito constitucional insculpido no inciso LVII do artigo $5^{\circ}$, segundo o qual "ninguém será considerado culpado até o trânsito em julgado de sentença penal condenatória" (BRASIL, 2015a, p. 15).

Ainda sobre o caso, apesar de a decisão não ter gerado efeito vinculante, enquadrou-se na repercussão geral e abriu portas para discussões que perduram até o presente momento, em virtude da recente sentença de condenação do ex-presidente Luiz Inácio Lula da Silva. Neste cenário, alguns dos ministros, dentre os quais Gilmar Mendes, tem se posicionado no sentido de se rever tal decisão, já que a presunção de inocência é um princípio constitucional.

Para o procurador de Justiça Rômulo de Andrade Moreira, membro do Ministério Público baiano, os membros do STF usaram a prerrogativa constitucional de intérpretes da Constituição contra o princípio democrático e questionou, há época, a referida decisão na Comissão Interamericana de Direitos Humanos, ligada à Organização dos Estados Americanos (OEA) (LUCHETE, 2016).

Veja-se, portanto, que se tem desenvolvido uma visão controversa acerca da mutação constitucional. A princípio, o que para muitos seria um instituto apto para buscar a efetividade das normas constitucionais, em especial daquelas que definem direitos fundamentais, acaba por criar, de fato, uma celeuma acerca da vertente adequada à própria teoria da decisão judicial, já que denota um viés discricionário por parte da atuação da corte constitucional brasileira.

Muitos são os críticos que se colocam contrários à produção das mutações constitucionais, dentre eles, Lenio Luiz Streck, criador da teoria Crítica Hermenêutica do Direito, conforme análise a ser realizada neste estudo em tópico específico. Um dos argumentos de tal teoria é que as decisões judiciais, uma vez que é produzida a partir de uma discricionariedade do julgador, passa a se revestir de um pesado conteúdo político e valorativo, levando a uma crença de que o Direito não tem autonomia suficiente para que se produzam decisões coerentes em âmbito de jurisdição constitucional (STRECK, 2014). Justamente, a mutação constitucional é produto dessa discricionariedade.

Toda a celeuma, de fato, emerge em um cenário de transformações nos ideários de cunho teórico, filosófico e ideológico do Direito, decorrentes do fracasso e insuficiência dos preceitos do positivismo e a consequente ascensão do chamado neopositivismo e as influências desse processo na teoria da decisão judicial, conforme se verá no próximo tópico.

\section{A TEORIA DA DECISÃO JUDICIAL NO PERCURSO ENTRE O POSITIVISMO E O PÓS-POSITIVISMO}

A teoria da decisão judicial é um dos aspectos da teoria do Direito que mais tem provocado discussões no cenário brasileiro nos últimos tempos. Como alude Luiz (2013, p. 126):

A falta de preocupação sobre a questão de como o direito é efetivamente aplicado faz qualquer teoria padecer da cisão entre a razão prática e a razão teórica, apostando-se nesta e expurgando aquela para fora do direito. [...] Se o juiz é aquele que decide sobre o caso, dando sentido ao Direito, então quais são as 
condições de possibilidade do magistrado em assim agir? Aqui está o objetivo da construção de uma teoria da decisão judicial.

De fato, o aspecto da decisão judicial foi pouco abordado durante o desenvolvimento do próprio positivismo. E nesta esfera, que é a do exercício da interpretação pelo julgador, que se torna imperativo que a hermenêutica crie uma forma de constrangimento epistemológico sobre a interpretação (STRECK, 2017a). Entretanto, para que se possa compreender a exata dimensão do problema, que está intimamente ligada ao tema do trabalho - mutação constitucional - é preciso que se faça uma breve incursão histórica sobre o papel do juiz nas correntes positivistas, até que se chegue ao chamado "pós-positivismo".

O positivismo científico, desenvolvido no século XIX, não distinguia lei de Direito. $\mathrm{Na}$ França, foi nomeado exegetismo, na Alemanha, pandectismo e na Inglaterra, jurisprudência analítica. Para esse pensamento, o papel do juiz reduzia-se à subsunção, sendo-lhe vedado fazer discursos de validade do Direito. Foi, assim, uma crença marcada por um Direito sem lacunas (STRECK, 2017a).

Importa mencionar que no século XX surgiram as teorias positivistas pós-exegéticas, dentre elas as de Hans Kelsen e de Herbert Hart, ambas tratadas neste trabalho, especificamente, sob o prisma da decisão judicial.

Kelsen foi um positivista normativista. Rompeu com o paradigma exegético. Sua grande contribuição foi estabelecer a distinção entre Direito e Ciência do Direito. O Direito como linguagem-objeto, a Ciência do Direito, como a metalinguagem. Sua conhecida "teoria pura" tratava da pureza no âmbito da Ciência do Direito e não do seu objeto, o Direito, razão pela qual não separava Direito e Moral. Apesar de não haver em sua teoria uma preocupação com a interpretação nem com a aplicação do Direito, admitia que a interpretação do Direito encontravase eivada de subjetivismos advindos de uma razão prática solipsista, fato este que seria impossível de ser corrigido. A aplicação do Direito, assim, seria um ato de "política jurídica", envolvendo moral, política, ideologia, ou seja, o juiz realizaria um ato de vontade (STRECK, 2017a).

Na medida em que, na aplicação da lei, para além da necessária fixação da moldura dentro da qual se tem de manter $\mathrm{o}$ ato a pôr, possa ainda ter uma atividade cognoscitiva do órgão aplicador do Direito, não se tratará de um conhecimento do Direito Positivo, mas de outras normas que, aqui, no processo de criação jurídica, podem ter sua incidência: normas de Moral, normas de Justiça, juízos de valor sociais que costumamos designar por expressões correntes como bem comum, interesse do Estado, progresso, etc. (KELSEN, 2000, p. 393).

Streck (2017a) explica que Herbert Lionel Adolphus Hart foi o primeiro grande positivista pós-kelsiano, conhecido por suas teses de separação entre Direito Moral e pela sua teoria da discricionariedade judicial. Hart acreditava que sendo o direito identificado por uma prática social complexa (regra de reconhecimento), sua validade não decorreria de sua aceitação moral. Ademais, perante a indeterminação semântica da norma, haveria uma zona de textura aberta ao se tratar de 
casos difíceis (hard cases), situação em que o juiz teria discricionariedade para decidir. Hart (2009, p. 351) entendia que:

[...] sempre haverá, em qualquer sistema jurídico, casos não regulamentados juridicamente sobre os quais, em certos momentos, o direito não pode fundamentar uma decisão em nenhum sentido, mostrando-se o direito, portanto, parcialmente indeterminado ou incompleto. Para que possa proferir uma decisão em tais casos, o juiz não deverá declarar-se incompetente nem remeter os pontos não regulamentados ao poder legislativo para que este decida, como outrora defendia Bentham, mas terá de exercer sua discricionariedade e criar o direito referente àquele caso, em vez de simplesmente aplicar o direito estabelecido já existente. Assim, nesses casos não regulamentados juridicamente, o juiz ao mesmo tempo cria direito novo e aplica o direito estabelecido, o qual simultaneamente the outorga o poder de legislar e restringe esse poder.

Contudo, mesmo Hart (2009, p. 352) entendia haver limites ao poder de discricionariedade do juiz. Em suas palavras:

Assim, seus poderes são intersticiais, além de sujeitos a muitas restrições substantivas. Não obstante, haverá aspectos sobre os quais o direito existente não aponta nenhuma decisão como correta; e, para julgar essas causas, o juiz tem de exercer seu poder de criar o direito. Mas não deve fazê-lo arbitrariamente: isto é, deve ser sempre capaz de justificar sua decisão mediante algumas razões gerais e deve atuar como faria um legislador consciencioso, decidindo de acordo com suas próprias convicções e valores.

Pois bem. Os próximos capítulos da construção do pensamento jurídico contemporâneo acabaram por abranger diversas teses que buscaram refutar as ideias centrais do positivismo, especialmente, os modelos de Kelsen e Hart. Cristóvam (2016, p. 27) explica que "esse novo paradigma teórico pode ser designado simplesmente como pós-positivismo ou, a partir de uma expressão mais corrente, como neoconstitucionalismo". E acrescenta: "O paradigma neoconstitucionalista da teoria do Direito propõe um amplo redimensionamento da noção de sistema jurídico, a partir da estreita relação entre direito e moral”. Streck (2017a, p. 211), neste cenário, esclarece que:

O pós-positivismo não se apresentava como uma corrente necessariamente contrária ao Positivismo. Seu objetivo era trazer a lume o que ficava escondido sob o véu da neutralidade, tal como a sujeição do conhecimento científico as contingências históricas e, como consequência, os problemas relativos aos métodos de investigação/experimentação. [...] O pós-positivismo no Direito pode ser compreendido com um amplo movimento (tentativa de) ruptura/superação do Positivismo Jurídico, evidenciando as limitações deste paradigma ante a complexidade do mundo hodierno.

Streck (2017a, p. 220) alerta que "a superação do positivismo implica o enfrentamento do problema da discricionariedade judicial, o que em termos filosóficos se apresenta como o problema 
do solipsismo da razão prática”. Além disso, o autor chama a atenção para as ambiguidades que podem decorrer do termo neoconstitucionalismo:

Esse belo epíteto - cunhado por um grupo de constitucionalistas espanhóis embora tenha representado um importante passo para a afirmação da força normativa da Constituição na Europa continental, no Brasil, acabou por incentivar/institucionalizar uma recepção acrítica da Jurisprudência dos Valores, da teoria da argumentação de Robert Alexy (que cunhou o procedimento da ponderação como instrumento pretensamente racionalizador da decisão judicial) e do ativismo judicial norte-americano (STRECK, 2014, p. 46).

Por esta razão, o autor optou pelo termo Constitucionalismo Contemporâneo ao invés de constitucionalismo, para referir-se ao movimento que tomou forma com o advento das constituições surgidas após a Segunda Guerra Mundial e que ainda está presente no cenário atual (STRECK, 2014). É justamente no contexto do Constitucionalismo Contemporâneo que a interpretação constitucional e a teoria da decisão passam a ser tratadas sob o enfoque de diferentes teorias, dentre as quais, duas delas interessam neste momento para que se possa, no tópico seguinte, compreender a Crítica Hermenêutica do Direito. São elas: a teoria da Argumentação Jurídica de Robert Alexy (Alemanha) e a Teoria Interpretativa de Ronald Dworkin (Estados Unidos).

Dworkin iniciou um intenso debate com Hart, inclusive no que tange ao aspecto da discricionariedade judicial. Dworkin (2010) entende que se vive hoje em uma comunidade de princípios, cujos membros se reconhecem reciprocamente como livres e iguais, com respeito pelas diferenças. Isso significa que os direitos fundamentais - a igualdade e a liberdade reciprocamente reconhecidas a todos em uma comunidade - são compreendidos como princípios opostos e complementares entre si, capazes, por consequência, de gerar tensões. Todas as normas, até mesmo as regras, nada mais são do que densificações desses princípios. Nesse cenário, surge sua teoria interpretativa da única resposta correta: em havendo mais de uma possiblidade juridicamente defensável, decorrente de tensões, o direito sempre tem uma resposta. Durante a interpretação, deve-se buscar uma aplicação racional da norma, a partir da análise da situação individual específica, irrepetível e única sob o ponto de vista de todos os envolvidos, com vistas à garantia da integridade do direito, ou seja, a segurança de uma decisão fundada em uma norma previamente aprovada e na justiça no caso concreto.

Melhor explicando, o direito é um conceito de interpretação emanado pelas instituições jurídicas e "as questões a ele relativas encontram, necessariamente, respostas nas leis, nos princípios constitucionais, nos regulamentos e nos precedentes que tenham DNA constitucional, e não na vontade individual do aplicador" (STRECK, 2013, p. 343-367).

A partir deste posicionamento, pode-se dizer que o direito, enquanto um sistema de regras e princípios, não se abre a um juízo discricionário, já que tem sempre uma história institucional a ser reconstruída e que indica a melhor decisão a ser tomada. Ademais, vale mencionar que Dworkin entendia a decisão judicial como ato de responsabilidade política: "nos campos da lógica, da filosofia da linguagem, da teoria da norma, da decisão judicial, da filosofia moral e política, 
além da metaética." (STRECK, 2017a, p. 253).

Por seu turno, Robert Alexy, que se autodenominou "não positivista inclusivo"2 se apoiou em diversos aspectos da teoria hartiana, em especial, no que se refere à decisão judicial. Robert Alexy aceitou plenamente a visão de Herbert Hart acerca da textura aberta do direito, porta de entrada para elementos morais ou questões de justiça no âmbito do direito. Nessa perspectiva entende que os casos difíceis não podem ser resolvidos por elementos exclusivos do direito, e neste caso a moral deve prevalecer na tomada de decisão. Nestes termos, defendeu o papel corretivo da Moral.

Este aspecto, entretanto, foi rechaçado por Dworkin, no sentido de que, para ele, o conteúdo moral do Direito não o transforma em Moral. O direito continua a operar como tal, de forma que sua aplicação possa se dar dentro de um patamar de segurança jurídica, sem dar abertura a pretensões abusivas (DWORKIN, 2010).

Outro aspecto relevante na teoria alexyana, em especial no que diz respeito à sua teoria dos direitos fundamentais ${ }^{3}$ é a cisão entre regras e princípios. Dalla Barba (2017, p. 101) explica que para Alexy:

[...] regras são normas que podem ser satisfeitas ou não satisfeitas de maneira definitiva, ou seja, se uma regra prevê determinada hipótese, a ocorrência fática daquilo que é previsto importa em sua aplicação exatamente naquilo que exige; os princípios, ao contrário, são normas que ordenam que algo deva ser realizado na maior medida possível dentro das possibilidades jurídicas e fáticas, consistindo em mandamentos de otimização, portanto. Assim, caso haja um conflito entre duas regras, a solução encontrada por Alexy é a introdução de uma cláusula de exceção que possa eliminar a controvérsia, eliminando a regra declarada inválida do ordenamento jurídico. Os princípios, ao contrário, quando entram em colisão não o fazem na dimensão da validade, mas na dimensão de peso e, dessa forma, aquele princípio que restar prejudicado não é extirpado do ordenamento jurídico justamente por sua característica (distinta da regra) de operar como mandamento de otimização.

Entretanto, nos chamados hard cases, em que as questões acabem transcendendo o plano das regras positivadas, ou seja, naquelas situações em que emerge um conflito entre direitos fundamentais, Alexy valeu-se da ideia do sopesamento dos princípios em colisão. Ainda de acordo com Dalla Barba (2017, p. 102):

Essa metodologia conduz Alexy a estabelecer uma máxima responsável por determinar a proporcionalidade dos pesos dos princípios colidentes, traduzindo-

2

No debate envolvendo separação ou não entre Direito e Moral, outros positivismos surgiram: o inclusivo e o exclusivo. O positivismo inclusivo, representado por Jules Coleman, mantém o apego às fontes sociais do Direito e recorre a Hart para dizer que a regra do reconhecimento, em casos explícitos, pode permitir que princípios morais possam ser aceitos como juridicamente obrigatórios. Aceita a discricionariedade de forma moderada e entende que os fatores morais incluídos no Direito limitariam a atuação dos juízes em suas decisões. Já o positivismo exclusivo, defendido por Joseph Raz defende a separação radical entre Moral e Direito. Admite a discricionariedade e entende que o Direito não é capaz de reivindicar autoridade se tiver princípios morais como critérios de validade (STRECK, 2014).

3 Esta explicação é fundamental para que se possa entender como o Supremo Tribunal Federal acatou esta teoria de forma distorcida. E esta distorção tornou-se um canal aberto para a produção de mutações constitucionais. 
se em sua "lei do sopesamento" que pode ser exteriorizada através de fórmulas aritméticas. Entabuladas as possibilidades fáticas e jurídicas possíveis por meio da utilização da máxima da proporcionalidade, daquele princípio que atender da melhor maneira o impasse em questão será possível articular um preceito que, fundamentado procedimental e argumentativamente, será aplicado ao caso concreto silogisticamente, como no caso das regras. Entretanto, nos casos de equivalência entre os princípios em colisão surge um impasse epistemológico que leva Alexy a confirmar a existência daquilo que chamou de "discricionariedade estrutural", permitindo ao legislador ou tribunal agir ou não agir.

Contudo, um dos aspectos apontados como falhos em termos da teoria alexyana, tanto sob o prisma da teoria de Dworkin quanto de Streck é que:

Esgotados os limites epistêmico-metodológicos da máxima proporcionalidade, a questão da discricionariedade é direcionada para a teoria da argumentação, cujos critérios discursivos ficam responsáveis por estabelecer uma espécie de filtro dos argumentos racionais aptos a alicerçar a decisão judicial (DALLA BARBA, 2017, p. 102).

Ou seja, estabelecer regras para a argumentação que venham a criar um controle da fundamentação das decisões judiciais, não significa eliminar as incertezas advindas da prática interpretativa e da própria norma. Isso recai, fatalmente, na discricionariedade.

Veja-se, então, que neste percurso histórico pode-se observar que, com exceção à teoria de Dworkin, todas as outras acabaram por desaguar na discricionariedade judicial.

\subsection{O Neoconstitucionalismo e a Nova Hermenêutica: parâmetros de interpretação adotados pelo Supremo Tribunal Federal}

A visão voltada à necessidade de interpretação da constituição, em virtude de se considerála como norma suprema, só veio a ser consolidada na segunda metade do século XX, mais precisamente após os anos 50. O direito constitucional, até então, era um direito sem interpretação (PEREZ ROYO, 2014).

Até meados do século XX, os métodos tradicionais de interpretação jurídica buscavam a neutralidade em sua aplicação, afastando valores, inclusive, já que integrados em plena teoria positivista. Acontece que, em se tratando de interpretação das constituições, acabaram tornandose insuficientes em muitas situações, já que prezavam pela simples subsunção do caso à norma (BARROSO, 2013).

No exercício interpretativo a partir da visão tradicional, portanto, percebe-se que a análise do caso concreto perante a norma converge para a subsunção. Este padrão interpretativo, típico do positivismo jurídico, perdurou até que a dinâmica social mostrou sua insuficiência diante dos novos fatos da vida. Barroso (2013, p. 334) ilustra bem este cenário: “a nova interpretação constitucional 
surge para atender às demandas de uma sociedade que se tornou bem mais complexa e plural”.

No Brasil, os novos paradigmas hermenêuticos superaram os conceitos do pensamento jurídico clássico no final do século XX, com a finalidade de adotar uma postura mais lógica, criativa e justa quando da interpretação constitucional. Neste cenário, Barroso (2013) leciona que emergem três novos paradigmas hermenêuticos: a superação do formalismo jurídico, a nova cultura jurídica pós-positivista e a ascensão do direito público e a centralidade da Constituição.

A superação do formalismo jurídico ocorreu por meio do abandono da ideia clássica de que o Direito era a expressão máxima da razão e justiça, e que sempre haveria uma norma perfeita no ordenamento jurídico para que o juiz realizasse a subsunção. Com o advento do pensamento neopositivista, houve uma mudança de perspectiva no direito. A ciência, que classicamente era voltada para as relações privadas, passou a valorizar as normas de caráter público, o que resultou em uma visão de centralidade e primazia da Constituição. E atrelado a esta ideia, entendeu-se que qualquer interpretação jurídica deveria ser realizada nos parâmetros dos valores e princípios da Constituição (BARROSO, 2013).

Barroso (2013) aponta outros fatores que influenciaram a adoção de novos elementos de interpretação constitucional, alegando que esta não derrota a interpretação tradicional, mas emerge com vistas a suprir necessidades deficientemente supridas pelo modelo clássico. A nova interpretação surge, assim, para lidar com os casos difíceis, para os quais não existe solução prépronta no ordenamento.

Existem três situações que levam aos casos difíceis: a) ambiguidade da linguagem, ou seja, termos com múltiplos significados ou indeterminados, que só podem ser definidos junto ao caso concreto, como, por exemplo: servidor público, relevância e urgência; interesse social; b) desacordos morais razoáveis, típicos das sociedades plurais e complexas, nas quais se pensa de maneira diferente sobre temas moralmente controvertidos, como eutanásia, descriminalização das drogas leves; c) conflitos de normas constitucionais ou de direitos fundamentais, o que pode acarretar tensões (BARROSO, 2013).

Vale acrescentar que a importância da interpretação constitucional recai com maior ênfase no âmbito de possíveis tensões entre direitos fundamentais, perante casos concretos nos quais não há uma solução clara na lei. E Barroso (2013), neste contexto, acredita que a nova hermenêutica jurídica incorpora um modelo destinado justamente a lidar com casos complexos de uma sociedade cada vez mais dinâmica. Trata-se da normatividade dos princípios, do ajustamento das colisões de normas constitucionais e da ponderação e argumentação jurídica, elementos que derivam da teoria de Robert Alexy.

A norma não possui normatividade suficiente até que seja integrada pelos fatos, o problema se torna parte da norma e o intérprete torna-se coparticipante do processo de criação do direito relacionado ao caso concreto. Sua pré-compreensão, seus valores ganham importância. A norma é produzida, portanto, a partir do caso concreto (BARROSO, 2013).

Ainda nas palavras de Barroso (2013), assume papel de importância na prática interpretativa, a ponderação ou sopesamento, que na tradição alemã, consiste em um aspecto do 
princípio da proporcionalidade. Neste cenário, vale ressaltar que, para Alexy (LIMA, 2008), a ponderação envolve a busca da solução ótima quando se depara com princípios concorrentes e o princípio da proporcionalidade é a chave para que se possa resolver a ponderação.

Tratando com mais detalhes sobre a ponderação proposta por Alexy, Barroso (2013) explica que é uma técnica interpretativa para dirimir conflito de normas constitucionais, mormente sobre direitos fundamentais. Exerce-se mediante concessões recíprocas, sendo realizada em três etapas: a) identificam-se as normas relevantes aplicadas ao caso; b) identificam-se os fatos relevantes; c) testam-se as soluções possíveis para ver a que melhor se coaduna com o conjunto da Constituição.

A argumentação jurídica é outro elemento integrante dos novos paradigmas da Hermenêutica da Constituição. Tendo em vista que a regra geral que legitima a função jurisdicional é a separação de poderes - o Legislativo faz as leis; o juiz não cria o direito, mas o aplica de acordo com as regras do representante que criou o direito - na hipótese de o juiz como coparticipante do processo de criação da norma, a legitimação da sua atuação não pode se fundar somente na separação dos poderes, pelo fato de ele estar criando o direito sem o batismo da representação popular (BARROSO, 2013).

Ademais, Barroso (2013) se pauta nas lições de Alexy sobre a superação da separação entre Direito e Moral, alegando que quando a norma não fornece a resposta, é necessário que o Direito se aproxime da filosofia moral. Como consequência do neopositivismo, a lei não perde sua importância, mas o Direito não cabe mais integralmente na norma jurídica, o valor justiça está além dela. E corroborando com este pensamento, Mendes e Branco (2014) enfatiza que é típica das constituições atuais a incorporação de valores morais ao domínio jurídico, não se limitando as Constituições a somente limitar a atuação do Estado e a discriminar competências. Para o autor, "as constituições contemporâneas absorvem noções de conteúdo axiológico e, com isso, trazem para a realidade do aplicador do direito, debates políticos e morais” (MENDES; BRANCO, 2014, p. 81).

Importa, ainda, mencionar que Barroso (2017) defende que a atuação de uma corte constitucional deve se pautar em dois papeis: o contramajoritário e o representativo. No exercício do contramajoritário, o Supremo Tribunal Federal exerce o controle de constitucionalidade das normas, inclusive podendo invalidar aqueles emanados dos poderes Legislativo e do Executivo. Os fundamentos para isso, de acordo com o autor são: "a) a proteção dos direitos fundamentais; e b) a proteção das regras do jogo democrático e dos canais de participação política de todos." (BARROSO, 2017, p. 48-49).

No que tange ao papel representativo, o Ministro pontua que este precisa ser pensado em um paradigma diferente de separação de poderes, ou seja, a partir do pensamento de que somente aqueles eleitos pelo voto podem atuar como representantes dos interesses da sociedade. Ainda mais, considerando a crise de representação da atualidade, em que se questiona, inclusive, se, de fato, os legisladores representam a vontade popular (BARROSO, 2017). E complementa: "não é incomum nem surpreendente que o Judiciário, em certos contextos, seja melhor intérprete do 
sentimento majoritário.” (BARROSO, 2017, p. 55).

Vale ressaltar que, neste mesmo sentido, Urbinati (2006) defende que é possível, na contemporaneidade, construir uma representação democrática (ou advocacy, como prefere chamar) acoplando diferentes formatos, distintos da visão hegemônica predominante, ou seja, diferente daquela em que o Parlamento deve ser o cerne da vontade geral.

Depreende-se de tal pensamento, que a prática ativista/mutacional seria, portanto, decorrente do papel representativo do Supremo Tribunal Federal.

Pois bem. Controvérsias à parte, ainda que esse posicionamento represente um paradigma outro, e que possa, sim, ser capaz de propiciar a concretização de direitos de maneira mais efetiva, não há como negar que se trata de um modus operandi que converge, fatalmente, na discricionariedade judicial.

Mas, afinal, a prática ativista e mutacional é legítima ou constitui ação lesiva ao Estado Democrático de Direito? É o que será tratado nos próximos tópicos deste estudo, em especial, a partir dos fundamentos da teoria Crítica Hermenêutica do Direito.

\subsection{A Teoria da Decisão na Crítica Hermenêutica do Direito}

$\mathrm{Na}$ busca de respostas às indagações acerca da teoria do Direito, mormente, sobre a decisão judicial, de forma a pontuar a necessidade de se refutar a discricionariedade do juiz, o professor pós-doutor em Direito Lenio Luiz Streck construiu a chamada Crítica Hermenêutica do Direito (CHD).

Foi criada com a pretensão de fundar uma matriz teórica para o Direito, a partir dos aportes da filosofia, de forma a possibilitar uma análise crítica do direito. Baseou-se nas lições da filosofia hermenêutica de Martin Heidegger, Hans-Georg Gadamer, nas obras de Ernildo Stein e no pensamento de Luis Alberto Warat. Em um segundo momento, foram incorporados aportes de Ronald Dworkin para desenvolver sua teoria da decisão judicia (STRECK, 2017b).

Streck (2017b, p. 110) se vale da filosofia hermenêutica e da hermenêutica filosófica para superar o problema do solipsismo. Explica que:

Enquanto as múltiplas teorias que pretendem justificar o conhecimento buscam superar o sujeito solipsista, eliminando-o ou substituindo-o por estruturas comunicacionais, redes ou sistemas, e algumas, de forma mais radical, até mesmo por um realismo jurídico voluntarista (por todas, vale referir as teorias desconstrutivistas dos critical legal studies), a hermenêutica filosófica de Gadamer e a teoria integrativa de Dworkin, cada uma a seu modo, procuram controlar esse voluntarismo e essa subjetividade solipsista a partir da força da tradição, do círculo hermenêutico e da incindibilidade entre interpretação e aplicação. Por isso, a postura marcadamente antirrelativista, ponto comum nesses dois autores, é condição de possibilidade para superação do solipsismo e ponto a partir do qual se pode encontrar sempre decisões íntegras e coerentes em direito.

Ademais, a Crítica Hermenêutica do Direito, no que tange à decisão judicial, advogou 
em favor da tese da necessidade de respostas corretas em Direito, ou seja, constitucionalmente adequadas. Contudo, tal tese não constituiu uma simples adesão à proposta de Dworkin, já que este desenvolveu sua teoria nos aportes de outro sistema jurídico - o commom law, ou seja, a possibilidade de obter respostas corretas neste prisma vincula-se nos precedentes judiciais. A Crítica Hermenêutica do Direito, desenvolvida no Brasil, cujo sistema jurídico é a civil law, apoia-se na fundamentação/justificação da síntese hermenêutica que só acontece durante a aplicação da norma (STRECK, 2017a). Na busca da resposta correta (adequada à Constituição), Streck (2017a, p. 259) estabelece cinco princípios fundantes para a decisão jurídica:

Princípio um: a preservação da autonomia do Direito; Princípio dois: o controle hermenêutico da interpretação constitucional - a superação da discricionariedade; Princípio três: o respeito à integridade e à coerência do Direito; Princípio quatro: $\mathrm{o}$ dever fundamental de justificar as decisões; Princípio cinco: o direito fundamental a uma resposta constitucionalmente adequada.

Há de se pontuar, ainda, alguns aspectos inerentes à ideia de resposta correta no âmbito da Crítica Hermenêutica do Direito:

Resposta correta está ligada à superação do objetivismo e do subjetivismo. Por isso a noção de resposta correta é incompatível com pragmaticismos, realismos e todas as formas de positivismo. Resposta correta quer dizer que esta - a resposta - nunca advirá antes das perguntas serem feitas. Perguntas implicam estabelecimento de critérios para encontrar respostas adequadas. (STRECK, 2017a, p. 258).

Streck (2017a), além disso, admite que a judicialização da política seja fator normal em uma sociedade, quanto mais plural como a brasileira, em que, em muitas situações os poderes políticos não conseguem concretizar os preceitos constitucionais. Contudo, não se pode, durante a decisão judicial, extrapolar os limites dessa judicialização, incorrendo no ativismo judicial, que, pode levar, fatalmente, à produção de mutações constitucionais, ferindo o princípio da separação dos poderes e, por consequência, o Estado Democrático de Direito. É a partir desta análise que o autor propõe três indagações fundamentais que um juiz deverá responder que poderão orientá-lo na prevenção das práticas ativistas:

Se está diante de um direito fundamental com exigibilidade, se o atendimento a esse pedido pode ser, em situações similares universalizado, quer dizer, concedido às demais pessoas e se, para atender aquele direito, está-se ou não fazendo uma transferência ilegal-constitucional de recursos, que fere a igualdade e a isonomia. [...] sendo uma das três perguntas respondidas negativamente, estar-se-á com razoável grau de certeza, em face de uma atitude ativista (STRECK, 2017a, p. 259). 
Veja-se, portanto, que sob o prisma da Crítica Hermenêutica do Direito, a mutação constitucional emerge de uma atuação discricionária do Supremo Tribunal, decorrente de prática ativista, oferecendo risco de colapso ao Estado Democrático do Direito.

\subsection{Mutações Constitucionais e Críticas à Atuação do Supremo Tribunal Federal à Luz da Teoria Crítica Hermenêutica do Direito}

A respeito da prática judicial brasileira em âmbito de jurisdição constitucional, especialmente, Streck (2014) pontua que o Supremo Tribunal Federal, no desiderato de dirimir as tensões entre normas constitucionais, em especial, aquelas definidoras de direitos fundamentais, tem incorrido em três recepções equivocadas: a Jurisprudência dos Valores, o ativismo norteamericano e a ponderação alexyana. O autor explica que:

No caso alemão, a Jurisprudência dos Valores serviu para equalizar a tensão produzida depois da outorga da Grundegesetz pelos aliados em 1949. Com efeito, nos anos que sucederam à consagração da lei fundamental, houve um esforço considerável por parte do Bundesverfassungsgericht para legitimar uma Carta que não tinha sido constituída pela ampla participação do povo alemão. Daí a afirmação de um jus distinto da lex, ou seja, a invocação de argumentos que permitissem ao Tribunal recorrer a critérios decisórios que se encontravam fora da estrutura rígida da legalidade. A referência a valores aparece, assim, como mecanismo de abertura de uma legalidade extremamente fechada (STRECK, 2014, p. 58).

Observa-se que no Brasil, incorporou-se a ideia de uma Constituição como ordem de valores e de uma atuação interpretativa no sentido de se encontrar tais interesses. A esta visão, aparentemente, atrelou-se a teoria da argumentação de Alexy.

Veja-se que Alexy pretendeu racionalizar a ponderação de valores, mas no Brasil, esses pressupostos racionalizadores não são levados em conta, acarretando, na verdade, um retorno à Jurisprudência dos Valores (STRECK, 2014).

Ainda há se pontuar que a recepção equivocada da ideia de ponderação levou ao chamado panprincipiologismo, que de acordo com Streck (2014, p. 60), trata-se de "uma proliferação descontrolada de enunciados para resolver determinados problemas concretos, muitas vezes ao alvedrio da própria legalidade constitucional”.

Lima (2008), no mesmo sentido, pontua que a teoria dos princípios de Alexy é aplicada de forma distorcida no Brasil. Para o autor, um dos problemas na atuação da corte constitucional brasileira repousa na insuficiência de uma argumentação jurídica objetiva e transparente. Justificase, exaustivamente, a existência da colisão entre os direitos envolvidos nos casos submetidos a julgamento, mas negligencia-se a consistente fundamentação na escolha do direito adequado.

Vigora na atuação do Supremo Tribunal Federal a teoria (jogo) da Katchanga ${ }^{4}$. Ou seja,

4 Para melhor compreensão, segue a anedota da "teoria da Katchanga". 
não é suficiente pensar que se aprendeu a jogar a Katchanga. O jogo é mais complexo do que se supõe, uma vez que a própria Katchanga Real representa um problema a ser decifrado. E aponta um exemplo ilustrativo deste pensamento, que foi o caso da pesagem dos botijões de gás, tratado pela ADI 855-2/DF, em que o Estado do Paraná havia criado uma lei que obrigava os revendedores de gás a pesarem os botijões na presença do consumidor. Tal lei seguiu os devidos preceitos do processo legislativo. Mas, o Supremo Tribunal Federal considerou a norma inconstitucional, irrazoável e não proporcional, sem, no entanto, explicar na decisão quais os aspectos da razoabilidade e da proporcionalidade foi violado.

Outra ideia recepcionada no Brasil de maneira equivocada foi a do ativismo judicial norte americano, que também se desenvolveu em um cenário histórico de necessidades específicas daquela realidade. Mas no País, tem decorrido de uma postura decisionista/discricionária dos magistrados (STRECK, 2014).

Streck (2014) rechaça de maneira enfática a postura adotada pela corte constitucional brasileira, fundada na discricionariedade e na ponderação de valores alexyana (à brasileira), pontuando para uma interpretação que venha a convergir no direito como integridade, buscando trazer elementos capazes de condicionar o processo decisório, na defesa de argumentos de princípios que sejam aplicados de maneira coerente, segundo prática jurídica, ou seja, uma aplicação condizente com a racionalidade jurídica.

Ora, se, ao fim e ao cabo, cabe ao intérprete hierarquizar (e escolher) o princípio aplicável, a pergunta inexorável é: qual a diferença entre o intérprete ponderador e o interprete do positivismo, que discricionariamente escolhe qual a melhor interpretação? (STRECK, 2013, p. 354).

Portanto, sob a perspectiva da Crítica Hermenêutica do Direito, o Supremo Tribunal Federal está longe de representar uma ruptura com o positivismo. Pelo contrário, suas decisões, em especial as que levam à produção das mutações constitucionais, vêm sendo pautadas nos parâmetros da discricionariedade judicial. Tal postura, que para os julgadores, refletem no esforço de se trazer

\footnotetext{
Um rico senhor chega a um cassino e senta-se sozinho em uma mesa no canto do salão principal. O dono do cassino, percebendo que aquela seria uma ótima oportunidade de tirar um pouco do dinheiro do homem rico, perguntou se ele não desejaria jogar.

- Temos roleta, blackjack, texas holden' e o que mais lhe interessar, disse o dono do Cassino.

- Nada disso me interessa, respondeu o cliente. Só jogo a Katchanga.

O dono do cassino perguntou para todos os crupiês lá presentes se algum deles conhecia a tal da Katchanga. Nada. Ninguém sabia que diabo de jogo era aquele.

Então, o dono do cassino teve uma idéia. Disse para os melhores crupiês jogarem a tal da Katchanga com o cliente mesmo sem conhecer as regras para tentar entender o jogo e assim que eles dominassem as técnicas básicas, tentariam extrair o máximo de dinheiro possível daquele "pote do ouro".

E assim foi feito.

Na primeira mão, o cliente deu as cartas e, do nada, gritou: “Katchanga!” E levou todo o dinheiro que estava na mesa.

Na segunda mão, a mesma coisa. Katchanga! E novamente o cliente limpou a mesa.

Assim foi durante a noite toda. Sempre o rico senhor dava o seu grito de Katchanga e ficava com o dinheiro dos incrédulos e confusos crupiês.

De repente, um dos crupiês teve uma idéia. Seria mais rápido do que o homem rico. Assim que as cartas foram distribuídas, o crupiê rapidamente gritou com ar de superioridade: "Katchanga!"

Já ia pegar o dinheiro da mesa quando o homem rico, com uma voz mansa mas segura, disse: "Espere aí. Eu tenho uma Katchanga Real!". E mais uma vez levou todo o dinheiro da mesa...

Observa-se a partir da anedota que não é suficiente pensar que se aprendeu a jogar a Katchanga. O jogo é mais complexo do que se supõe, uma vez que a própria Katchanga Real representa um problema a ser decifrado. Eis a atuação da corte constitucional brasileira. Desconhecem-se as regras (LIMA, 2008).
} 
efetividade às normas constitucionais, em especial, àquelas definidoras de direitos fundamentais, bem como agir quando há inércia dos poderes políticos em prol desta efetividade, na verdade, tem acarretado prejuízos ao princípio democrático e ao da separação dos poderes. Melhor dizendo, sob tal perspectiva, a mutação constitucional constitui, inexoravelmente, um mecanismo lesivo ao Estado Democrático de Direito.

Streck, Lima e Oliveira (2007, p. 61), acerca da mutação constitucional, pontuam que:

A tese da mutação constitucional advoga em última análise uma concepção decisionista da jurisdição e contribui para a compreensão das cortes constitucionais como poderes constituintes permanentes. Ora, um tribunal não pode mudar a constituição; um tribunal não pode "inventar" o direito: este não é seu legítimo papel como poder jurisdicional, numa democracia. A atividade jurisdicional, mesmo a das cortes constitucionais, não é legislativa, muito menos constituinte. De uma perspectiva interna ao direito, e que visa a reforçar a normatividade da constituição, o papel da jurisdição é o de levar adiante a tarefa de construir interpretativamente, com a participação da sociedade, o sentido normativo da constituição e do projeto de sociedade democrática a ela subjacente. Um tribunal não pode paradoxalmente subverter a constituição sob o argumento de a estar garantindo ou guardando. Há, portanto, uma diferença de princípio entre legislação e jurisdição (Dworkin). O "dizer em concreto" significa a não submissão dos destinatários - os cidadãos - a conceitos abstratalizados. A Suprema Corte não legisla (muito embora as súmulas vinculantes, por exemplo, tenham adquirido explícito caráter normativo em terrae brasilis).

Em suma, para a Crítica Hermenêutica do Direito, a mutação constitucional decorre, de uma noção distorcida do papel do juiz enquanto coparticipante do processo de criação da norma, precipuamente no controle de constitucionalidade das leis - sua atribuição principal conferida pela Constituição no caput do artigo 102 da Constituição Federal (BRASIL, 2015a). É prática que configura ativismo judicial. Ora, na medida em que a discricionariedade é regra nas decisões do STF, difícil imaginar como isso não levaria à arbitrariedade. Neste cenário, Streck (2014, p. 64-65) ainda pontua que:

[...] a atuação ativista por parte do Supremo Tribunal Federal demonstra a falta de limites no processo interpretativo. Veja-se que sequer os limites semânticos do texto constitucional funcionam como bloqueio ao protagonismo judicial que vem sendo praticado em todas as esferas do Poder Judiciário em terrae brasilis.

Neste contexto, o autor levanta a necessidade de se propor uma interpretação pautada nos ensinamentos da Crítica Hermenêutica do Direito, no sentido de uma racionalidade jurídica, ou seja, de se proferir decisões que reconheçam os direitos efetivamente, não os criar com base em argumentos de natureza subjetiva ou política, impondo-se como limites os princípios da democracia e da separação dos poderes (STRECK, 2014).

Decidir é agir com responsabilidade política. Responsabilidade de meio, de construir a resposta correta a partir da melhor interpretação possível do material 
jurídico básico (leis, códigos, precedentes etc.) e dos princípios que conformam esse empreendimento coletivo (que remetem, por sua vez, a dimensões da dignidade humana) (STRECK, 2017a, p. 268).

Por fim, cabe ressaltar a necessidade de uma reflexão séria sobre a postura judicial brasileira, reflexão esta que deve partir dos próprios julgadores, de forma a preservar o Estado Democrático de Direito e, por consequência, efetivem os direitos fundamentais. Por mais que o modus operandi dos ministros do Supremo Tribunal Federal atenda ao seu papel contramajoritário e tenha por objetivo à efetivação das normas constitucionais - o que é natural em decorrência da vasta judicialização da política e das relações sociais - o fato é que um agir discricionário pode se abrir a abusos. É neste contexto que o aporte fornecido pela Crítica Hermenêutica do Direito pode orientar a atuação do Judiciário de forma a atender aos preceitos do Estado Democrático de Direito.

Considerando, ademais, a importância de poderes políticos atuantes e atentos à dinâmica social. Este é um fator essencial para a redução da judicialização e, por consequência, das práticas ativistas/mutacionais.

\section{CONCLUSÃO}

Diante de todo o exposto, concluiu-se que o aumento da judicialização das relações políticas e sociais, levou o Supremo Tribunal Federal a um papel de destaque no atual cenário brasileiro, de forma que cabe à Corte cumprir seu papel contramajoritário.

Observou-se, ainda, que existe uma visão sobre a atuação do Supremo Tribunal Federal - dentre os próprios ministros, em especial, Luís Roberto Barroso - de que a corte constitucional também possui um papel representativo, dada a falência em termos de representação do parlamento. Em decorrência disso, a partir de um novo prisma de separação de poderes, a corte constitucional poderia ser melhor intérprete do sentimento majoritário do que os representantes eleitos. Neste cenário, então, ativismo e mutação constitucional seriam práticas corriqueiras, inerentes à própria judicialização.

Entretanto, por mais que uma atuação fundada neste pensamento possa levar a resultados positivos em termos de efetivação das normas constitucionais, especialmente, daquelas definidoras de direitos fundamentais, na medida em que o modus operandi interpretativo do Supremo Tribunal Federal converge, fatalmente, na discricionariedade judicial, não há como afastar o risco de abuso. $\mathrm{O}$ julgador não pode estar autorizado a decidir conforme a sua vontade ou a sua consciência. $\mathrm{O}$ julgar é um ato de responsabilidade que deve considerar a lei e a Constituição, de forma a evitar decisões lesivas ao Estado Democrático de Direito.

A Crítica Hermenêutica do Direito é uma teoria frutífera no sentido de orientar a teoria da decisão no Brasil, na medida em que advoga por uma ação julgadora pautada na ideia de intersubjetividade e sem perder de vista alguns princípios fulcrais: preservação da autonomia do Direito; controle hermenêutico da interpretação constitucional - a superação da discricionariedade; 
respeito à integridade e à coerência do Direito; dever fundamental de justificar as decisões; o direito fundamental a uma resposta constitucionalmente adequada.

Por outro lado, por mais que sob o prisma da Crítica Hermenêutica do Direito, a produção de mutações constitucionais seja considerada prática ativista e, portanto, ilegítima, não se pode desconsiderar a importância do instituto mutacional como fator de atualização da Constituição, para fins de efetivação de suas normas.

Ademais, a sensibilização por parte dos poderes Legislativo e Executivo às novas demandas de uma sociedade plural, de maneira a atuarem de forma mais dinâmica, pode reduzir o grau de judicialização e, por consequência, de certa forma, limitar a atuação do Judiciário em questões que podem ser dirimidas pelos próprios poderes políticos.

\section{REFERÊNCIAS}

BARROSO, Luís Roberto. A razão sem voto: o Supremo Tribunal Federal e o governo da maioria. In: VIEIRA, Oscar Vilhena; GLEZER, Rubens (org.). A razão e o voto: diálogos constitucionais com Luís Roberto Barroso. São Paulo: FGV, 2017. p. 22-77.

BARROSO, Luís Roberto. Curso de direito constitucional contemporâneo. São Paulo: Saraiva, 2013.

BONAVIDES, Paulo. Curso de direito constitucional. 18. ed. São Paulo: Malheiros, 2006.

BRASIL. [Constituição (1988)]. Constituição da República Federativa do Brasil. Organizado por Alexandre de Moraes. São Paulo: Atlas, 2015a.

BRASIL. Supremo Tribunal Federal. Habeas corpus 126292. Relator: Ministro Teori Zavascki. São Paulo, 2015b. Disponível em: http:/www.stf.jus.br/portal/processo/verProcessoAndamento. asp?numero $=126292 \&$ classe $=\mathrm{HC} \&$ origem $=\mathrm{AP} \&$ recurso $=0 \&$ tipoJulgamento $=\mathrm{M}$. Acesso em: 2 set. 2016.

BULOS, Uadi Lammêgo. Direito constitucional ao alcance de todos. 6. ed. São Paulo: Saraiva, 2015.

CRISTÓVAM, José Sérgio da Silva. Princípios constitucionais: razoabilidade, proporcionalidade e argumentação jurídica. 2. ed. Curitiba: Juruá, 2016.

DALLA BARBA, Rafael Giorgio. Nas fronteiras da argumentação: a discricionariedade judicial na teoria discursiva de Robert Alexy. Salvador: Juspodivm, 2017.

DWORKIN, Ronald. Levando os direitos a sério. 3. ed. São Paulo: Martins Fontes, 2010.

HART, Herbert Lionel Adolphu. O conceito de direito. São Paulo: Martins Fontes, 2009.

KELSEN, Hans. Teoria pura do Direito. São Paulo: Martins Fontes, 2000.

KUBLISCKAS, Wellington Márcio. Emendas e mutações constitucionais: análise dos mecanismos de alteração formal e informal da Constituição Federal de 1988. São Paulo: Atlas, 2009. 
LASSALLE, Ferdinand. A essência da constituição. Rio de Janeiro: Lumen Juris, 2013.

LENZA, Pedro. Direito constitucional esquematizado. 20. ed. São Paulo: Saraiva, 2016.

LIMA, George Marmelstein. Alexy à brasileira ou a Teoria da Katchanga. In: LIMA, George Marmlstein. Direitos Fundamentais.net. [S. l.], 18 set. 2008. Disponível em: https:// direitosfundamentais.net/2008/09/18/alexy-a-brasileira-ou-a-teoria-da-katchanga/. Acesso em: 29 abr. 2017.

LUCHETE, Felipe. Membro do MP vai a comissão da OEA contra prisão antes de trânsito em julgado. Consultor Jurídico, [S. l.], 26 fev. 2016. Disponível em: http://www.conjur.com. br/2016-fev-26/membro-mp-corte-oea-prisao-antes-coisa-julgada. Acesso em: 28 fev. 2016.

LUIZ, Fernando Vieira. Teoria da decisão judicial: dos paradigmas de Ricardo Lorenzetti à resposta adequada à Constituição de Lenio Streck. Porto Alegre: Livraria do Advogado, 2013.

MENDES, Gilmar Ferreira; BRANCO, Paulo Gustavo G. Curso de direito constitucional. 9. ed. São Paulo: Saraiva, 2014.

PEREZ ROYO, Javier. Curso de derecho constitucional. 14. ed. Madrid: Marcial Pons, 2014.

SÁNCHEZ URRUTIA, Ana Victoria. Mutación constitucional y fuerza normativa de la constitución: una aproximación al origen del concepto. Revista Española de Derecho Constitucional, Madrid, v. 20, n. 58, p. 105-135, enero/abr. 2000.

STRECK, Lenio Luiz. Dicionário de hermenêutica: quarenta temas fundamentais da teoria do direito à luz da crítica hermenêutica do direito. Belo Horizonte: Casa do Direito, 2017a.

STRECK, Lenio Luiz. Hermenêutica e jurisdição: diálogos com Lenio Streck. Porto Alegre: Livraria do Advogado, 2017b.

STRECK, Lenio Luiz. Porque a discricionariedade é um grave problema para Dworkin e não o é para Alexy. Revista Direito e Práxis, Rio de Janeiro, v. 4, n. 2, p. 343-367, 2013.

STRECK, Lenio Luiz. Verdade e consenso: constituição, hermenêutica e teorias discursivas. 5. ed. São Paulo: Saraiva, 2014.

STRECK, Lenio Luiz; LIMA, Martonio Mont'Alverne Barreto; OLIVEIRA, Marcelo Andrade Cattoni de. A nova perspectiva do Supremo Tribunal Federal sobre controle difuso: mutação constitucional e limites da legitimidade da jurisdição constitucional. Argumenta Journal Law, Jacarezinho, n. 7, p. 45-68, 2007.

URBINATI, Nadia. Representative democracy: principles and genealogy. Chicago: Chicago University Press, 2006.

Como citar: COSTA, Patrícia Spagnolo Parise; LACERDA, Murilo Couto; LINO, Estefânia Naiara da Silva. Análise das mutações constitucionais à luz da crítica hermenêutica do Direito. Revista do Direito Público,Londrina, v. 15, n. 1, p. 61-84, abr. 2020. DOI: 10.5433/24157-108104-1.2020v15n1p. 61. ISSN: 1980-511X 
Recebido em: 08/10/2018

Aprovado em: 28/02/2019 